\title{
Identifying and Modelling the Dynamic Response of Leaf Water Content to Water Temperature in Hydroponic Tomato Plant
}

\author{
Diyah YumeInA and Tetsuo Morimoto \\ Department of Biomechanical Systems, Ehime University, Matsuyama, Ehime 790-8566, Japan
}

(Received August 20, 2016; Accepted October 16, 2016)

\begin{abstract}
In this paper, we identified and modelled the short-term response of leaf water content to water temperature in hydroponic tomato plants using a neural network. Leaf water content was estimated from leaf thickness using an eddy current-type displacement sensor. Dynamic changes in the leaf water content of the tomato plants, as affected by water temperatures, was identified and modelled using a neural network. A three-layered neural network with optimal system order and hidden neuron number allowed nonlinearity of this system to be successfully identified. The estimated responses obtained from model simulation were correlated closely with the observed responses. Leaf water content increased with water temperature up to $35^{\circ} \mathrm{C}$ in a short period of several hours. At a water temperature above $35^{\circ} \mathrm{C}$, however, leaf water content decreased with increasing water temperature. Leaf water content, including root water uptake, of tomato plants is significantly suppressed by high water temperature. The relationship between water temperature and leaf water content over a short-term of several hours is represented by a hill-shaped curve (nonlinear curve) and reaches maximum value when the water temperature is about $35^{\circ} \mathrm{C}$. These dynamic and static relationships between water temperature and leaf water content were successfully confirmed from model simulation.
\end{abstract}

Keywords : dynamic response, identification, model, neural networks

\section{INTRODUCTION}

Hydroponic culture techniques have several potential advantages over soil culture techniques for cultivation, e.g., technical ease of flexible control of the root-zone environment (Gale and Ben-Asher, 1983; Raviv and Lieth, 2007). Promoting growth and producing high quality plants can also be expected through optimal control of the root-zone environment.

In order to realize an effective control such as an optimal control, it is important to make a dynamic model of plant response to root-zone environment and then understand the dynamic and static characteristics between these two variables in more detail.

In the root-zone environment in hydroponics, water temperature is one of the major manipulating factors for controlling plant growth and development, because it is easy to control using a heater and a cooler. Optimal control of water temperature brings about good fruit ripening with no reduction in growth or fruit set. Ikeda and Osawa (1984) reported that root temperature is an important factor that directly affects plant growth. Root temperature also affects many physiological processes such as respiration (Jensen, 1960), water absorption (Unger and Danielson, 1967), nutrient uptake (Hussain and Maqsood, 2011) and water movement and transpiration (Gray, 1941). Davis and Lingle (1961) elicited increased growth with warmed roots $\left(25^{-}-30^{\circ} \mathrm{C}\right)$ and decreased growth when roots were cooled below $15^{\circ} \mathrm{C}$ (Martin and Wilcox, 1963). Although water temperature has been shown to affect plant growth, the physiological basis for the dynamic response in controlling the plant production system has not been thoroughly investigated.

Leaf water content, on the other hand, is one of the most important control factors for optimizing growth in plants, because it significantly affects both the quantity and quality of plants (Nonami, 1998). It is, however, difficult to directly and continuously measure the dynamic change in leaf water content of an intact whole plant, without damaging the plant. Leaf thickness is used as a sensitive indicator for estimating leaf water content of plants. Meidner (1990), Syverrtsen and Levy (1982) and Búrquez (1987) used indirect methods for monitoring water status based on using displacement transducers to measure swelling and shrinkage in a wide range of plant tissue such as in leaves. In this study, therefore, the leaf water content was estimated from leaf thickness. An eddy current-type displacement sensor allows the leaf thickness to be measured in a continuous and non-destructive manner.

Many researchers have modelled the process of water movement in plants, including root water uptake, using mathematical approaches (Gardner, 1991; Roose and Fowler, 2004; Doussan et al., 2006; Foster and Miklavcic, 2013). They applied mathematical equations to build models of the static relationships between input factors and output factors. However, it is thought that modeling the dynamic behaviors of the physiological- ecological proc-

Corresponding author: Tetsuo Morimoto, fax: + 81-89-946-9823, e-mail : morimoto@agr.ehime-u.ac.jp 
esses of plants (e.g., leaf water content to water temperature) using conventional mathematical approaches characterized by deterministic parameters and mathematical equations is fundamentally difficult. This difficulty is because the physiological-ecological processes have complex properties, such as strong nonlinearity and time-variation, and unknown factors (Whittaker, 1990). Another method for constructing a dynamic model is system identification that deals with unknown processes. The identification methods have been applied to plant production systems (Morimoto et al., 1996; 2003; Morimoto and Hashimoto, 2000). It is possible to adapt the time-variation of the physiological status of a plant if the identification procedure is repeated periodically as the plant grows.

Neural networks have been used for system identification of complex systems (Chen et al., 1990; Narendra and Parthasarathy, 1990). They are powerful tools for identifying complex systems characterized by non-linearity because they can acquire such nonlinear characteristics using their own high learning capabilities (Rumelhart et al., 1986). In a plant production system, therefore, artificial neural networks have been widely applied to identify the physiological responses of plant (Morimoto et al., 1996; 2003; Qiao et al., 2010; Hatzig et al., 2015; Ghamarnia and Jalili, 2015).

The objective of this study is to measure the dynamic responses of the leaf water content of tomato plants in a non-destructive manner, as affected by water temperature, using an eddy current-type displacement sensor and then make a dynamic model using a neural network. Furthermore, the dynamic and static relationships between water temperature and leaf water content, including water movement from root to leaf, over a short-term of several hours are investigated from the perspective of both observation and model simulation.

\section{MATERIALS AND METHODS}

\section{Plant material and measuring system}

The experiment was conducted in a growth chamber at Ehime University from October to December, 2014. Plant materials were tomato plants (Lycopersicon esculentum
Mill. cv. Momotaro). Plants were grown using standard nutrient solution with an electrical conductivity (EC) set at $1.2 \mathrm{dS} \mathrm{m} \mathrm{m}^{-1}$. At $14 \mathrm{~d}$ after transplanting or when plant height reached about $20 \mathrm{~cm}$, plants were moved to a hydroponic system in a chamber (LHU-112M, TabaiEspec, Japan), where the air temperature and relative humidity were strictly controlled to a precision of $\pm 0.1^{\circ} \mathrm{C}$ and $\pm 3 \% \mathrm{RH}$, respectively. The light source was LED light of $100 \mu \mathrm{mol} \mathrm{m}{ }^{-2} \mathrm{~s}^{-1}$. The water temperature of the nutrient solution in the hydroponic system was controlled using a heater and a cooler.

\section{Leaf thickness measurement for estimating leaf water content}

Directly measuring the leaf water content of a plant in a non-destructive and continuous manner is usually difficult. Leaf thickness can be used as a sensitive indicator for estimating leaf water content of a plant (Búrquez, 1987; Meidner, 1990; McBurney, 1992). Figure 1 (a) and (b) show an overall appearance of the experimental system and a measuring method for leaf thickness. In this study, leaf thickness was measured as a change in leaf thickness $d$ in a continuous and non-destructive manner using an eddy current-type displacement sensor (PU-05, Applied Electronics Corp., Japan), as shown in Fig. 1 (b). Both a sensor head and a base were fixed and the change in leaf thickness $d$ was measured. It provides a suitable measuring technique for leaf thickness. An aluminum plate $(10 \times 10$ $\times 1 \mathrm{~mm}$ ) was put on a leaf and a high-frequency current was supplied to the coil inside the sensor head to generate a high-frequency electromagnetic field. When the target (magnetic substance) approaches this electromagnetic field, an eddy current-type displacement is generated on the surface of the target and changes the sensor coil impedance. The sensor system detects the resulting change in oscillation strength to identify the relationship between displacement and voltage. Leaf water content $(\%)$ was determined from the weight loss of the leaf using a heating and drying type infrared moisture meter (A\&D, MX-50) and then the relationship between leaf thickness and leaf water content was examined.

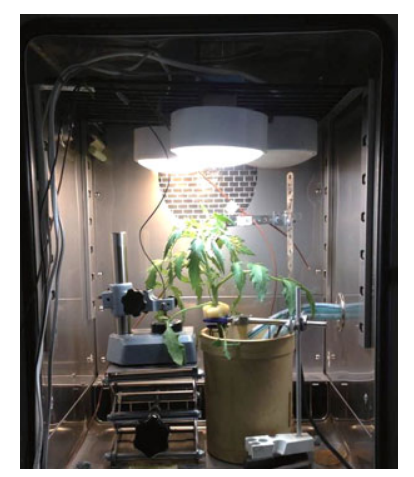

(a) Measuring and control system

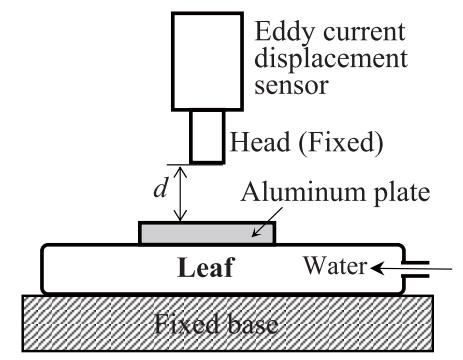

(b) A measuring method for leaf thickness using an eddy current displacement sensor

Fig. 1 Photograph of experimental apparatus and schematic diagram of leaf thickness measurement. 
$A$ water movement process $(A-B-C)$ of the plant from roots to leaf

It is important to express water movement of a plant systematically using a block diagram to well understand the dynamic characteristics of water movement from roots to leaves. Figure 2 (a) and (b) show a schematic diagram of water movement from roots to leaves in a plant and the block diagram of the water movement process consisting mainly of three processes (A, B, and C). Process A is the water uptake process by roots (input: water in the root zone, output: root water content), process B is the water movement process from roots to stem (input: root water content, output: stem water content), and process $\mathrm{C}$ is the water movement process from stem to leaf (input: stem water content, output: leaf water content). Final leaf water content is given by the difference between water quantity supplied to the leaf and transpiration. In this case, we assumed that transpiration is constant because light intensity is law and kept constant at a suitable level. In this study, water movement consisting of the three processes (A, B and $\mathrm{C}$ ), as shown in Fig. 2, was investigated using a whole plant, as shown in Fig. 2 (c). Furthermore, as shown in Fig. 2 (d), a cut-plant was used for investigating the dynamics of water movement of process $\mathrm{C}$ only. In this case, the petiole was dipped in water, which was absorbed through the xylem of the petiole.
Neural network application for dynamic identification

A neural network was used to create a dynamic model for simulation through learning (=identification), which predicts the response of leaf water content as affected by water temperature. In this study, a one-input (water temperature) and one-output (leaf water content) model was built.

Figure 3 shows a neural-network application for dynamic identification, where (a) is the input-output system considered here, and (b) is a three-layer neural network with time-delay operator for identifying this system. It is noted that the input-output system (a) represents one process expressing the water movement from roots to leaves, which was the integration of three processes (A, B, and C) in Fig. 2.

To identify dynamic responses, arbitrary feedback loops and time-delay operators for producing time histories (time-series) of the input and output data like an ARMA model are provided in the network (Chen et al., 1990; Isermann et al., 1997).

The dynamic response of the leaf water content LWC $(k)(k=1, \ldots, \mathrm{N})$ to water temperature $\mathrm{WT}(k)$ was identified and modelled using this neural network (Narendra and Parthasarathy, 1990; Isermann et al., 1997). The current output $\mathrm{LWC}(k)$ was estimated from historical input data $\{\mathrm{WT}(k), \mathrm{WT}(k-1), \ldots, \mathrm{WT}(k-n)\}$ and from past historical output data $\{\operatorname{LWC}(k-1), \ldots, \operatorname{LWC}(k-n)\}$. The learning

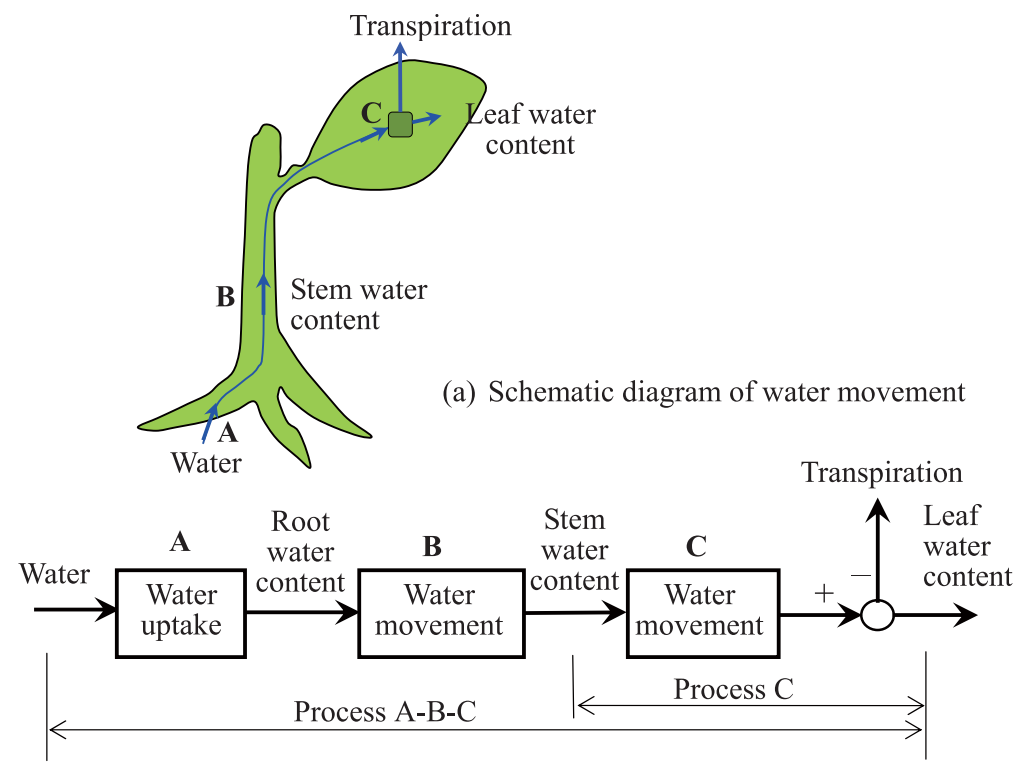

(b) Block diagram of a water movement process (A-B-C)

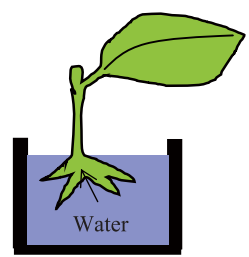

(c) Whole plant

(Process A-B-C)

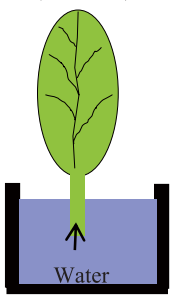

(d) Cut-leaf

(Process C)

Fig. 2 Block diagram of a water movement process from roots to leaves in a plant. 


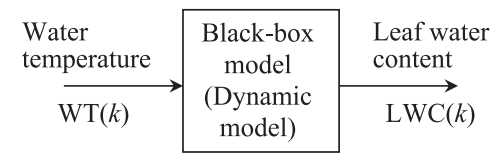

(a) A dynamic model with one input and one output

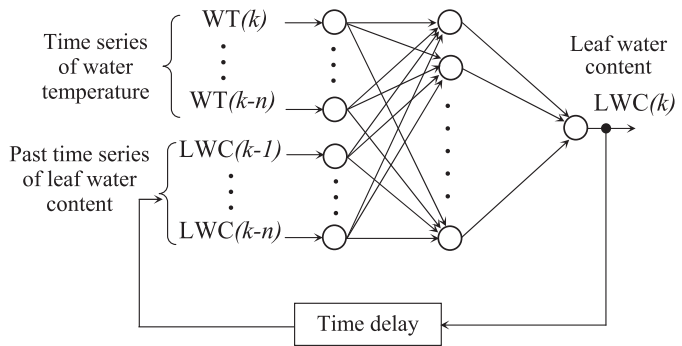

(b) A three-layered neural network for identifying a dynamic system

Fig. 3 Block diagram of a dynamic model with one input (water temperature), one output (leaf water content), and a time-delay neural network for identifying a dynamic model.

method was error back-propagation (Rumelhart et al., 1986).

$$
\begin{aligned}
\operatorname{LWC}(k)= & f \underbrace{(\operatorname{LWC}(k-1), \ldots, \operatorname{LWC}(k-n),}_{\text {Past time series of the output }} \\
& \underbrace{\mathrm{WT}(k), \mathrm{WT}(k-1), \cdots, \mathrm{WT}(k-n)}_{\text {Current and past time series of the input }})
\end{aligned}
$$

where $n$ is the system order (number of system parameters). The unknown function $f(\cdot)$ can be approximated by a neural network.

The input and output data were divided into two data sets, a training data set and a testing data set. The former was used for training the neural network, and the latter for evaluating the accuracy of the identified model. The testing data sets have to be independent from the training data sets. This type of model validation is called "crossvalidation".

The most important task in determining a model's structure is choosing the system parameter number (or system order). The system parameter number and the hiddenneuron number of the neural network were determined through trial and error based on cross-validation.

\section{RESULTS}

Relationship between leaf thickness and leaf water content

Leaf water content of the tomato plants was estimated from leaf thickness which allows continuous and nondestructive measurements. Figure 4 shows the relationship between the change in leaf thickness $(\mu \mathrm{m})$ and leaf water content $(\%)$ of the tomato leaves. It can be seen that the water content of the common leaves is more than $80 \%$. The correlation coefficient was $r^{2}=0.9826$. Both variables correlated closely and the relationship can be estimated by a linear line, as shown in the figure. Therefore, leaf water content can be estimated from leaf thickness.

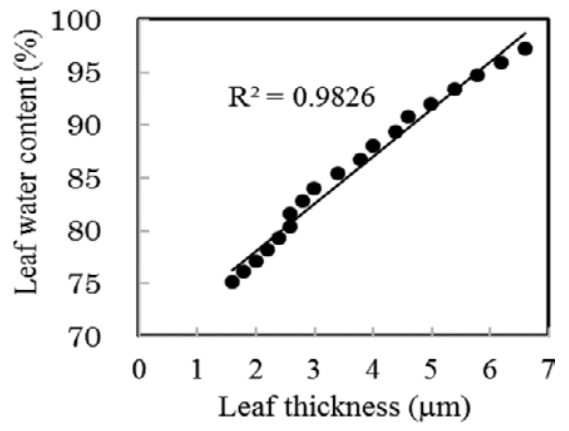

Fig. 4 Relationship between leaf thickness and leaf water content.

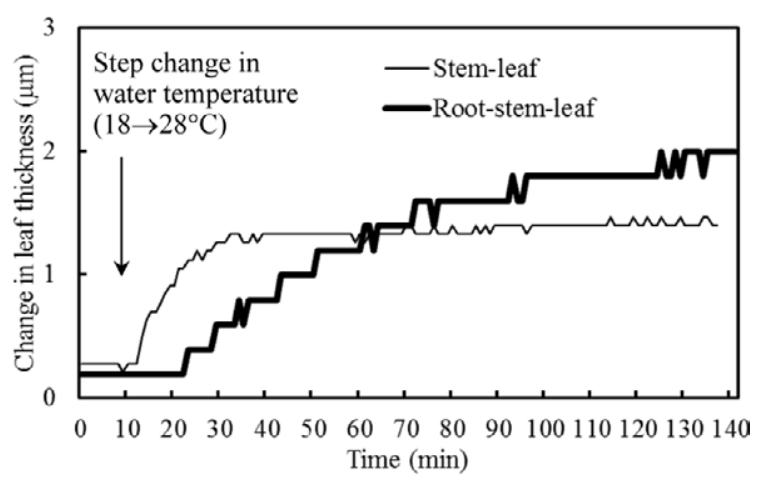

Fig. 5 Comparison of step responses of leaf water content to water temperature for a whole plant (process A-B-C) and cut-plant (process C) in hydroponics.

Fundamental responses of leaf water content to water temperature

Figure 5 shows the comparison of the step responses of leaf water content to water temperature for a whole plant (Fig. 2 (c)) and a cut-plant (Fig. 2 (d)) in hydroponics. Water temperature was changed from 18 to $29^{\circ} \mathrm{C}$ in a stepped manner. The bold line represents dipping the root of a whole plant in water, and the other line represents dipping only the stem of a cut-plant. Water movement in the former is a root-stem-leaf process including root water uptake (Ricardo et al., 2011), and that in the latter is a stemleaf process including stem (xylem) water absorption. Leaf water content usually depends on the valance between leaf transpiration and water supply to the leaf through the stem caused by root water uptake. Raising the water temperature from 18 to $29^{\circ} \mathrm{C}$ increased the leaf water content dynamically, which means that root water uptake is promoted by rising water temperature. The increase in the leaf water content was found to be about $10 \mathrm{~min}$ slower for the rootstem-leaf process (process A-B-C) than for the stem-leaf process (process $\mathrm{C}$ ).

Figure 6 shows the fundamental dynamic response of leaf water content to water temperature. Leaf water content was found to increase and decrease with water temperature, which means that root water uptake is promoted by rising water temperature. This finding can be explained by the thermal motion of water molecules becoming more active and water viscosity decreasing with rising water temperature. These results suggest that leaf water content can be 

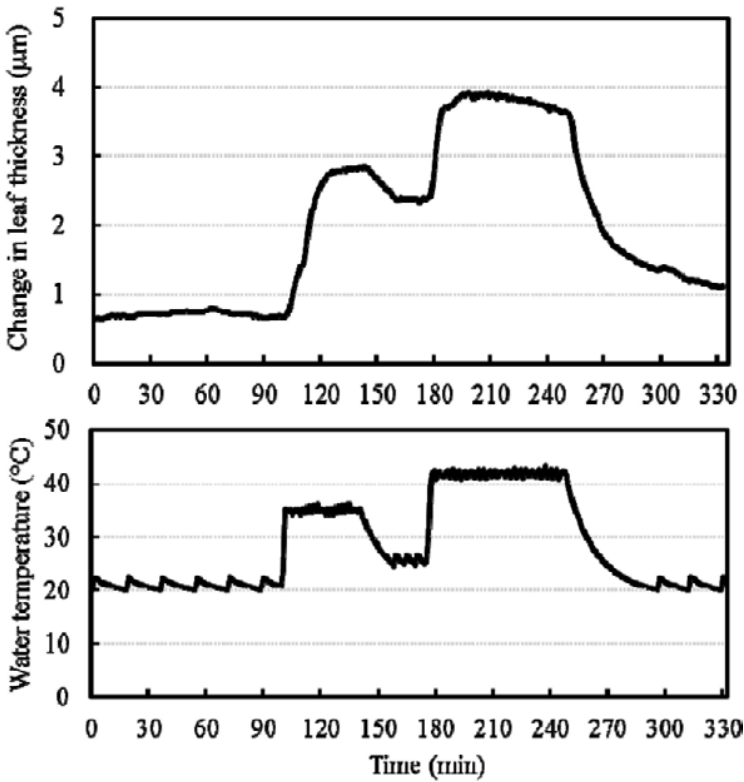

Fig. 6 Fundamental dynamic response of leaf water content to water temperature.

successfully controlled by water temperature.

Dynamic changes in leaf water content to water temperature for identification

In this study, eight types of dynamic responses of the input and output variables were obtained for learning of the neural network and one type of dynamic response was also obtained for validation of the identified-neural-network model. Figure 7 shows four types of typical dynamic responses of leaf water content in the tomato plants to changes in water temperature for $9 \mathrm{~h}$. It is noted that, in this figure, four types of typical patterns were chosen from eight types of patterns. From these responses, leaf water content was found to increase with water temperature at

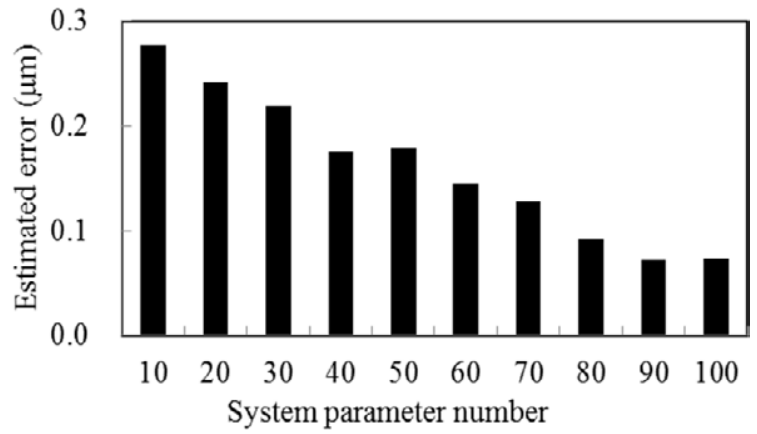

Fig. 8 Relationship between system parameter number and estimated error.

temperatures below $50^{\circ} \mathrm{C}$. However, a high water temperature of more than $60^{\circ} \mathrm{C}$ reduced leaf water content.

Leaf water content of the plant to water temperature was then identified by a neural network, and a black-box model for predicting the leaf water content of the plant was created. Furthermore, one type of dynamic response was used to confirm the model accuracy.

Identification results

The system parameter number (or system order) $n$ and the hidden-neuron number of the neural network $n_{h}$ were determined through cross-validation. Figure 8 shows the relationship between the system parameter number $n$ and the estimated error in identifying the testing data sets. Estimated error decreased with the system parameter number. However, there was no significant difference in the error when the system parameter number was more than 90 . Therefore, $n=90$ was selected as the suitable system parameter number. Figure 9 shows the relationship between the hidden-neuron number in the hidden layer $n_{h}$ and the estimated error. The estimated errors for the 10th hiddenneuron number gave a minimum error. Consequently, the system parameter number $n$ and the hidden neuron number

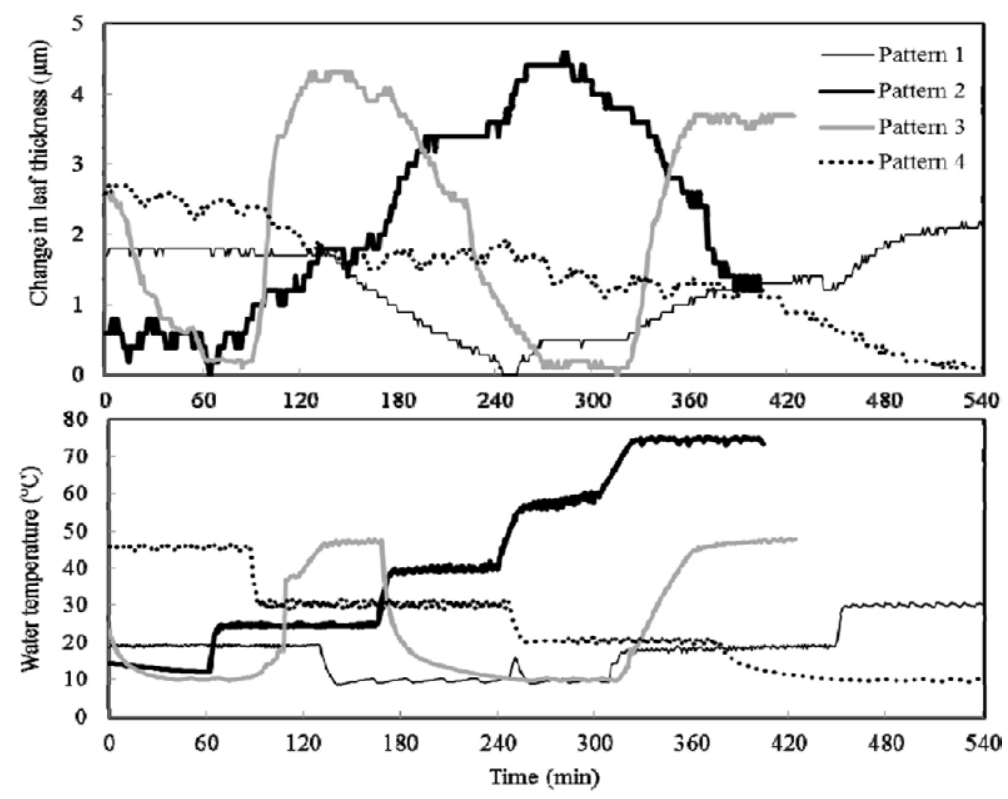

Fig. 7 Four types of typical dynamic changes in leaf water content of tomato plants grown in a hydroponic system, as well as water temperature, used for learning (identification). 


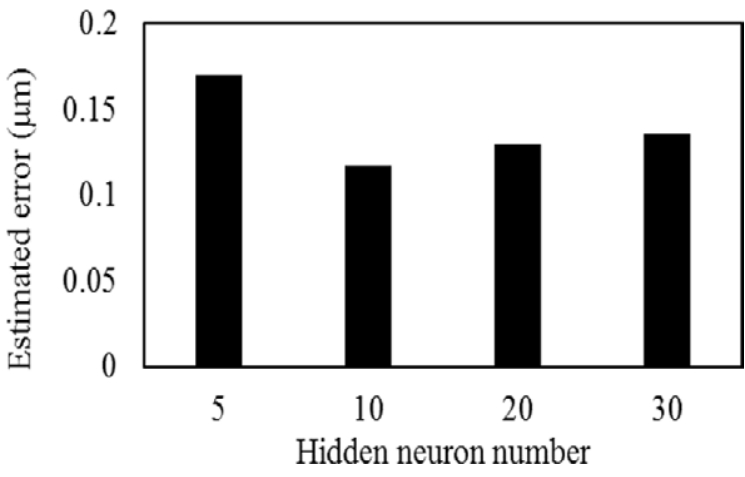

Fig. 9 Relationship between hidden neuron number and estimated error.

$n_{h}$ were determined to be 90 and 10 , respectively. These values minimized the error between the estimated and observed values in the testing data sets.

Next, the accuracy of the neural-network model identified here was evaluated using two methods. One compared the dynamic response of leaf water content to water temperature and the other compared the static relationship between water temperature and leaf water content.

Figure 10 shows the comparison of the estimated dynamic response, calculated from the neural network model, and the observed response for leaf water content. A testing data set, which is quite different from the training data sets, was used for this comparison. The estimated response correlated closely with the observed response.

Finally, the static relationship between water temperature and leaf water content was estimated using the identified neural-network model. Figure 11 shows the estimated step responses of leaf water content as affected by the step inputs of water temperature from 15 to $20,30,40,50$, and $60^{\circ} \mathrm{C}$. The step response becomes larger in the first half of the response as the step input of the water temperature becomes higher. At water temperatures above $40^{\circ} \mathrm{C}$, however, significant decreases in leaf water content were observed in the latter half of the response. These reductions are probably due to root water uptake being inhibited following the physiological disorder of the roots caused by high temperature.

Figure 12 (a) and (b) show the estimated and observed static relationships between water temperature and leaf water content in the tomato plants. The estimated values in Fig. 12 (a) were obtained at $180 \mathrm{~min}$ after the step input of water temperature in Fig. 11. From Fig. 12 (a), leaf water content increased until the water temperature reached about $35^{\circ} \mathrm{C}$. At a water temperature above $35^{\circ} \mathrm{C}$, however, leaf water content decreased with increasing water temperature. The same tendency was seen in the observed values in Fig. 12 (b). Thus, leaf water content, including root water uptake, of the tomato plants is significantly suppressed by high water temperature, and the relationship between water temperature and leaf water content is represented by a hillshaped curve with an optimum value of about $35^{\circ} \mathrm{C}$. This result was obtained from the response in the steady state over a short period of several hours. Comparing Fig. 12 (a) and (b), it can be seen that the estimated static relationship
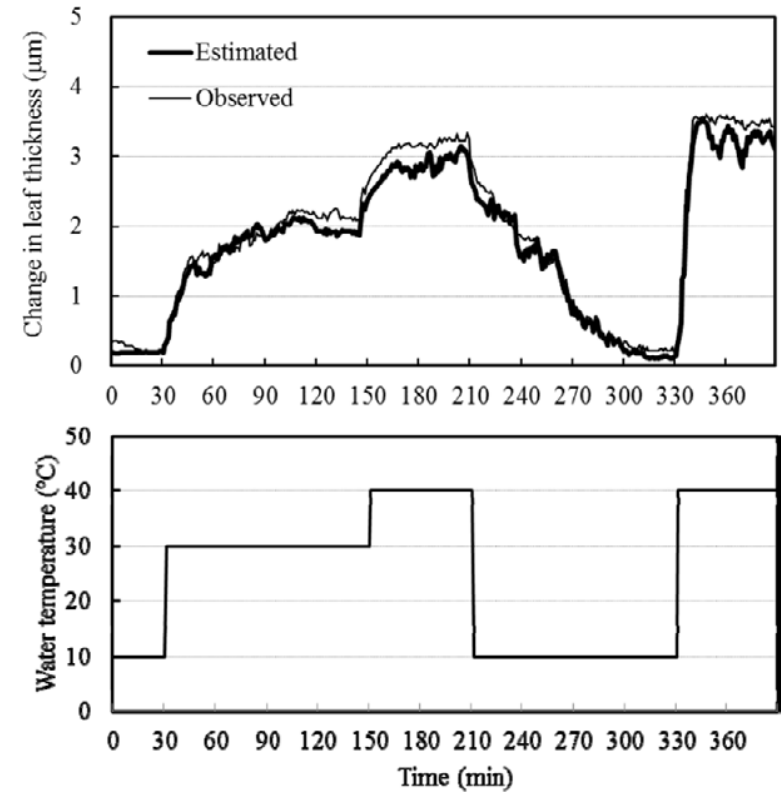

Fig. 10 Comparison of estimated response, calculated from the neural-network model, and observed response for leaf water content.
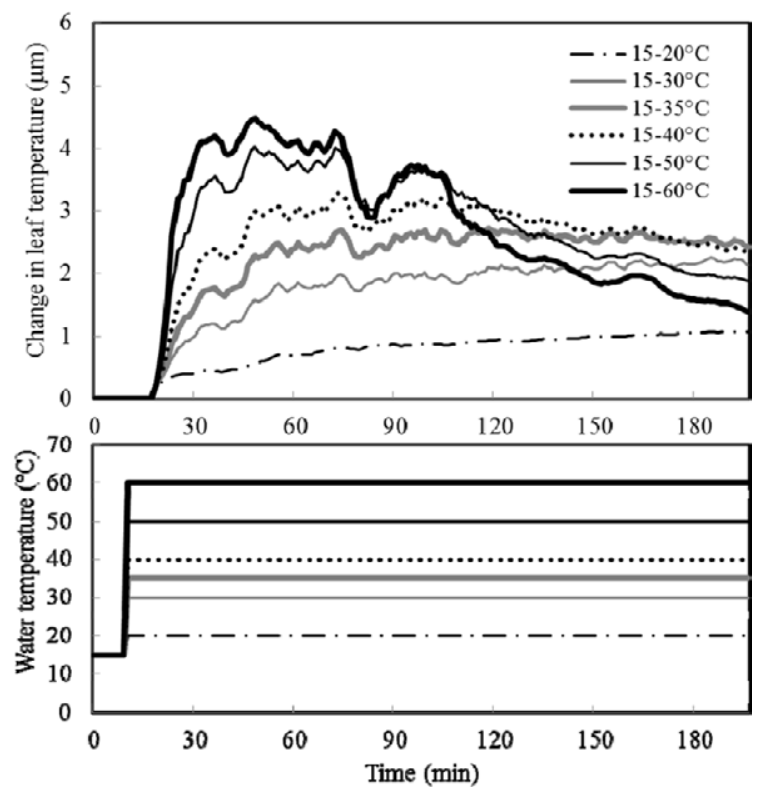

Fig. 11 Estimated step responses of leaf water content as affected by the step inputs of water temperature from 15 to $20,30,40,50$ and $60^{\circ} \mathrm{C}$ obtained from simulation.

is in fairly good agreement with the observed relationship.

Thus, from the good agreement between the estimated and observed responses in both the dynamic response in Fig. 10 and the static relationship in Fig. 12, a reliable dynamic model could be obtained for predicting the future behavior of leaf water content under any change in water temperature.

Figure 13 shows the observed static relationship between water temperature and leaf water content for a cutplant, where the stem (petiole) was dipped in water. Leaf water content increased with water temperature up to a high temperature of about $60^{\circ} \mathrm{C}$. Comparing two relationships 


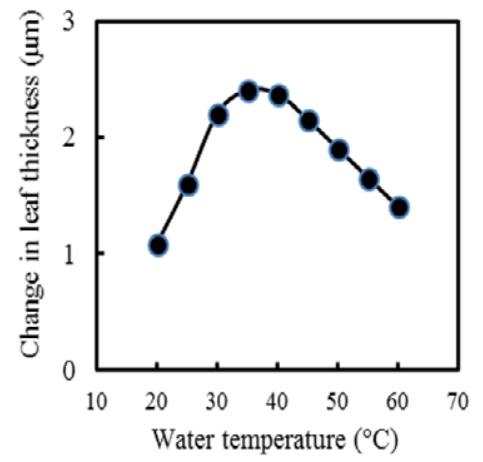

(a) Estimated data

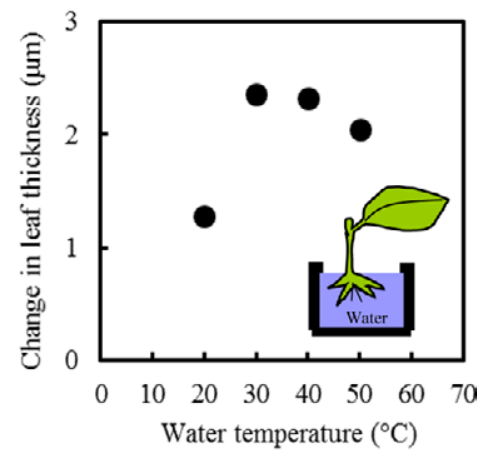

(b) Observed data

Fig. 12 Static relationship between water temperature and leaf water content for a whole plant.

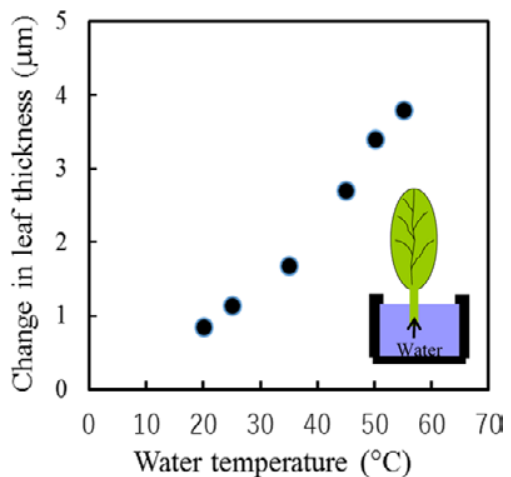

Fig. 13 Static relationship between water temperature and leaf water content for a cut-plant (Observed data).

in Figs. 12 and 13, water absorption by the stem (or petiole) was found to be less susceptible to high water temperature than that by roots.

\section{DISCUSSION}

Tomato plants are warm weather plants. Therefore, the optimal water temperature for long-term hydroponic cultivation is thought to be between 25 and $30^{\circ} \mathrm{C}$ (Boote et al., 1994). Hurewitz and Janes (1983) stated that the net photosynthetic rate of the leaves as well as photosynthate translocation increased with rising root-zone temperature up to $30^{\circ} \mathrm{C}$, and therefore, the optimal root-zone temperature for seedling growth of tomatoes was concluded to be around $30^{\circ} \mathrm{C}$. However, many growers consider that root activity such as water uptake at temperatures above $30^{\circ} \mathrm{C}$ or below $15^{\circ} \mathrm{C}$ is inhibited in many plants (Du and Tachibana, 1994). However, it is thought that this applies to long-term cultivation over several weeks (Falah et al., 2010). Our experiment was conducted within a day.

From our experiment, looking specifically at the static relationship between water temperature and leaf water content obtained from model simulation, leaf water content increased with water temperature up to approximately $35^{\circ} \mathrm{C}$, and then decreased with increasing water temperature (Fig. 12). Therefore, the optimal water temperature that maximizes the leaf water content of tomato plants is estimated to be around $35^{\circ} \mathrm{C}$ during a short-term of several hours.
This optimal temperature, the result of a short-term response, might be a little higher than a commonly used optimal temperature $\left(25^{-3} 0^{\circ} \mathrm{C}\right)$ (Cooper, 1973). However, Yoshida and Eguchi (1990) showed that root water uptake increased with water temperature up to $33^{\circ} \mathrm{C}$ in a response over several hours. Falah et al. (2010) also reported that the rate of root water uptake of tomato plants during a short period within a day was higher in $35^{\circ} \mathrm{C}$ water than in $22^{\circ} \mathrm{C}$ water. The reason that leaf water content increased with water temperature is because the thermal motion of water molecules becomes more active and water viscosity decreases with rising water temperature (Falah et al., 2010). Root water uptake is also thought to increase as root respiration increases with water temperature (Smakman and Hofstra, 1982; Du and Tachibana, 1994). However, high water temperatures above $35^{\circ} \mathrm{C}$ induce physiological disorders in the root system and results in lower leaf water content, because a high water temperature results in less dissolved oxygen in the hydroponic solution followed by decreased root respiration. Consequently, root uptake of water and various types of nutrient ions is inhibited. In a short period, leaf water content as a result of higher root water uptake is assumed to increase with water temperature up to approximately $35^{\circ} \mathrm{C}$, because a high water temperature has less effect (Hurewitz et al., 1984; Falah et al., 2010). However, long-term application of such high temperatures causes poorer growth of plants, which means that optimal water temperature for short-term dynamic control is different from that for long-term management. It is, therefore, emphasized that in a short period within a day, the root water uptake of tomato plants tends to increase with increasing water temperature close to $35^{\circ} \mathrm{C}$, whereas a water temperature above $25^{\circ} \mathrm{C}$ is usually unsuitable for long-term cultivation.

\section{CONCLUSION}

There was a close correlation between leaf water content and leaf thickness, showing a high correlation coefficient of $r^{2}=0.9826$. The leaf water content of hydroponic tomato plants was continuously and non-destructively estimated by measuring leaf thickness using an eddy currenttype displacement sensor. Many types of short-term 
dynamic responses of leaf water content, as affected by water temperature, could be obtained, allowing a successful dynamic model to be built using a neural network. A threelayered neural network in which both system order and hidden-neuron number were optimized was effective in making a model of such a complex system of leaf water content to water temperature. Both the estimated dynamic and static relationships between water temperature and leaf water content obtained from model simulation correlated closely with the observed relationships. Thus, it was shown that the neural-network model proposed here is suitable for identifying such complex dynamic processes as a water movement including water uptake by roots.

\section{REFERENCES}

Boote, K. J., Bennett, J. M., Sinclair, T. R., Paulsen, G. M. 1994. High temperature responses of crop plants. In "Physiology and Determination of Crop Yield" (ed. by Boote, K. J., Bennett, J. M., Sinclair, T. R., Paulsen, G. M.), Ed. American Society of Agronomy, Crop Science Society of America, Soil Science Society of America, Madison, WI, 365-389.

Búrquez, A. 1987. Leaf thickness and water deficit in plants: a tool for field studies. J. Exp. Bot. 38: 109-114.

Chen, S., Billings, S. A., Grant, P. M. 1990. Non-linear system identification using neural network. Int. J. Control 51: 11911214.

Cooper, A. J. 1973. Root temperature and plant growth. Research Review No. 4, Commonwealth Bureau Hortic. Plant. Crops, CABI Publishing, East Malling, UK, 73.

Davis, R. M., Lingle, J. C. 1961. Basis of shoot response to root temperature in tomato. Plant Physiol. 36: 153-162.

Doussan, C., Pierret, A., Garrigues, E., Pages, L. 2006. Water uptake by plant roots: II-Modelling of water transfer in the soil root-system with explicit account of flow within the root system-Comparison with experiments. Plant Soil 283: 99117.

Du, Y. C., Tachibana, S. 1994. Effect of supraoptimal root temperature on the growth, root respiration and sugar content of cucumber plants. Sci. Hortic. 58: 289-301.

Falah, M. A. F., Wajima, T., Yasutake, D., Sago, Y., Kitano, M. 2010. Responses of root uptake to high temperature of tomato plants (Lycopersicon esculentum Mill.) in soil-less culture. J. Agric. Technol. 6: 543-558.

Foster, K. J., Miklavcic, S. J. 2013. Mathematical mdelling of the uptake and transport of salt in plant roots. J. Theor. Biol. 336: $132-143$.

Gale, M. Z. J., Ben-Asher, J. 1983. Root aeration in a deep hydroponic system and its effect on growth and yield of tomato. Sci. Hortic. 19: 213-220.

Gardner, W. R. 1991. Modeling water uptake by roots. Irrig. Sci. 12: 109-114.

Ghamarnia, H., Jalili, Z. 2015. Artificial network for predicting water uptake under shallow saline ground water conditions. J. Sci. Res. Rep. 7: 359-372.

Gray, G. 1941. Transpiration in strawberries as affected by root temperature. Proc. Am. Soc. Hortic. Sci. 39: 269-273.

Hatzig, S. V., Schiessl, S., Stahl, A., Snowdon, R. 2015. Characterizing root response phenotypes by neural network analysis. J. Exp. Bot. 66: 5617-5624.

Hurewitz, J., Janes, H. W. 1983. Effect of altering the root-zone temperature on growth, translocation, carbon exchange rate, and leaf starch accumulation in the tomato. Plant Physiol. 73: 46-50.
Hurewitz, J., Maletta, M., Janes, H. W. 1984. The effects of root-zone heating at normal, and cool air temperatures on growth and photosynthetic rate of tomatoes. Acta Hortic. 148: 871-876.

Hussain, A., Maqsood, M. A. 2011. Root zone temperature influences nutrient accumulation and use in maize. Pakistan J. Bot. 43: 1551-1556.

Ikeda, H., Osawa, T. 1984. Lettuce growth as influenced by N source and temperature of nutrient solution. Proc. 6th Int. Conf. Soilless Culture 273-284.

Isermann, R., Ernst, S., Nelles, O. 1997. Identification with dynamic neural. Preprints of 11th IFAC Symp. Syst. Identification 3: 997-1022.

Jensen, G. 1960. Effects of temperature and shifts in temperature on the respiration of intact root systems. Physiol. Plant. 13: $822-830$.

Martin, G. C., Wilcox, G. E. 1963. Critical soil temperature for tomato plant growth. Soil Sci. Soc. Am. Proc. 27: 565-567.

McBurney, T. 1992. The relationship between leaf thickness and plant water potential. J. Exp. Bot. 43: 327-335.

Meidner, H. 1990. The absorption lag, epidermal turgor and stomata. J. Exp. Bot. 41: 1115-1118.

Morimoto, T., Hatou, K., Hashimoto, Y. 1996. Intelligent control for plant production system. Control Eng. Practice 4: 773784.

Morimoto, T., Hashimoto, Y. 2000. AI approaches to identification and control of total plant production systems. Control Eng. Practice 8: 555-567.

Morimoto, T., Tu, K., Hatou, K., Hashimoto, Y. 2003. Dynamic optimization using neural networks and genetic algorithms for tomato cool storage to minimize water loss. Trans. ASAE 46: 1151-1159.

Narendra, K. S., Parthasarathy, K. 1990. Identification and control of dynamical systems using neural networks. IEEE Trans. Syst. Man Cybern. 1: 4-27.

Nonami, H. 1998. Plant water relations and control of cell elongation at low water potentials. J. Plant Res. 111: 373-382.

Qiao, D. M., Shi, H. B., Pang, H. B., Qj, X. B., Plauborg, F. 2010. Estimating plant root water utake using a neural network approach. Agric. Water Manage. 98: 251-260.

Raviv, M., Lieth, J. H. 2007. Soilless Culture: Theory and Practice. Elsevier Science, Davis, U.S.A., pp 608.

Ricardo, A., Porcel, R., Ruiz-Lozano, J. M. 2011. Regulation of root water uptake under abiotic stress conditions. J. Exp. Bot. 13: $1-15$.

Roose, T., Fowler, A. C. 2004. A model for water uptake by plant roots. J. Theo. Biol. 228: 155-171.

Rumelhart, D. E., Hinton, G. E., Williams, R. J. 1986. Learning representation by back-propagation error. Nature 323: 533536.

Smakman, G., Hofstra, R. 1982. Energy metabolism of Plantago lanceolata, as affected by change in root temperature. Physiol. Plant. 56: 33-37.

Syverrtsen, J. P., Levy, Y. 1982. Diurnal changes in citrus leaf thickness, leaf water potential and leaf-to-air temperature difference. J. Exp. Bot. 135: 783-789.

Unger, P. W., Danielson, R. E. 1967. Water relations and growth of beans (Phaseolus vulgaris L.) as influenced by nutrient solution temperatures. Agron. J. 59: 143-146.

Yoshida, S., Eguchi, H. 1990. Root temperature effect on root hydraulic resistance in cucumber (Cucumis sativus L.) and figleaf gourd (Cucurbita ficifolia B.) plants. Biotronics 19: 121-127.

Whittaker, J. 1990. Graphical models in applied multivariate statistics. Wiley, 448. 